\title{
Paul Morphy
}

Viele sind berufes, doch wenige auserwählt.

Als Gott sein groBes Werk vollendet hatte, näherte sich ibm das Schach mit der Klage, daB es ohne Unterkunft sei, la es weder in den ernsten Palast der Wissenschaften, noch in des sehimmernde Heim der Kunst eingelassen werde: es sei aber seiner unwürdig, das gedankenarme Alltagsspiel zum Genossen zu haben!

Der Herr antwortete ihm: „Ich habe dir kein besonderes Heim gegeben, weil dein Gebiet kein scharf eingegrenztes ist, aber ich habe dich in Verwandtschaft gesetzt sowohl mit der Wissenschaft, als auch mit der Kunst. - Der einen kannst dn vorhalten, daB sie kaum logisch strenger denken kann, sls du, der anderen, daß du gensu solcheu GenuB bieten kannst, wie sie! Ein schönes Musikstück, ein Gedicht, ein farbenprachtiges Bild werden Tausenden von Kennern einen GenuB bereiten, aber auch das Nachspielen einer genial gespielton Schachpartie wird tausend Kundigen einen künstlerischen Genuß gewăhren. Und doch wirst du immer nur ein Stiefkind sein! Künstler werden bleibende Werte schaffen, włhrend deine Jünger, selbṣt wenn sie mit der Logik eines Gelehrten, mit der Phantasie eines Künstlers kampfen, nur einen Sieg oder eine Niederlage davontragen werden.

In Lande der Wissenschaft wird die leuchtende Fackel des Genies der nachfolgenden Generstion befabigter und minder bef khigter Manner den Weg weisen. In deinem Lande wird das Genie ein prächtig unterhaltendes, rasch verschwindendes Irrlicht sein, das viele in dein Land locken wird, um später traurig der groBen Leistung geringen Lohn zu empfangen. Deines Gebietes Fruchtlosigkeit wird gelästert, seine Schönheit jedoch wird stets bewundert werden. Eine verführerische Sirene wirst du sein. Viel Frende und Leid wirst du denen bereiten, die du in dein Herz schließt. Suche keine Unterkunft bei deinen stolzen Verwandten: es soll dir dafür eine Auszëichnung verliehen werden, mit welcher jene sich nicht brüsten können. In ihr Heim werden sich auch solche einschleichen, die nicht dahin hingehören. Kleine Leute werden als GröBen gefeiert werden, bei dir jedoch soll das Licht des wirklichen Talents die nachstrebenden Sohwachen stets in die richtige Beleuchtung setzen. GroBe Vertreter werde ich dir senden, die dich bald der Kunst, bald der Wissenschaft năher bringen, die bewunderungswürdige Dinge 
schaffen werden, ohne daB man sie für groBe Gelehrte oder groBe Künstler halten wird. Befriedigung muBt du in dir selbst suchen !“

Die Geschichte des Schachspieles lehrt, daB es wirklich so gekommen ist. Fast zu jeder Zeit gab es ausgezeichnete Vertreter, die das Schachspiel auf eine Höhe brachten, die es bald zur Wissenschaft, bald zur Kunst machte. Es gab Gelehrte und Künstler des Spieles. Zu den letzteren gehört Paul Morphy, der Auserwälte der Auserwählten!

Wie ein leuchtender Meteor erschien or am Himmel der Schachwelt, rasch verschwindend, aber ein ewiges Gedächtnis hinterlassend. Er war der Einzige, der Eigenartige, mit niemandem Vergleichbare. Eine Persönlichkeit auf dem Gebiete strenger Regeln!

Paul Charles Morphy wurde am 22. Juni 1837 in New Orleans geboren. Zehn Jahre alt, lernte er die Elemente des Spiels kennen; nach zwei Jahren beherrschte er bereits dessen Geheimnisse. Der zwölfjahrige „Wunderknabe“: besiegte seinen Lehrmeister und war ein Jahr spater bereits Meisterspieler.

Bis zum Jahre 1850 besuchte er die Schule in seiner Geburtsstadt; $1850-55$ bereitete er sich in dem St. Josephs College der Jesuiten in Spring Hill auf seine juristischen Studien vor. Von hier bezog er die Universitat von Louisiana und hatte nach kaum zwei Jahren das Dipiom zur Ausübung der Anwaltspraxis in seinem Heimatsstaate erworben, welches er jedoch nach dem Gesetz vor erlangter GroBjahrigkeit nicht benutzen durfte.

Günstige Vermögensverhaltnisse erlaubten es ibm, die Wartezeit sorglos der Erholung und Zerstreuupg widmen zu können. Der im Tahre 1857 in New York verenstaltete SchachkongreB und das damit verbundene Turnier bildeten den Wendepunkt seines Lebens.

Er hatte das Streben, emporzusteigen aus dem grauen Alltagsleben, zu berrschen mit dem Rechto des schaffenden, bildenden Genies. Der göttliche Funke in seiner Seele entbrannte mit elementarer Gewalt zur Flamme: er folgte den Lockungen der verführerischen Sirene, warf sich in ihre Arme, und mit unlösbaren Ketten blieb or auf ewig an sie gefesselt?

Es ist dies das Schicksal des geborenen Talents! - Auf ewig bleibt verborgen, was er wohl hatte leisten können, wenn ihn die Göttin Caissa nicht mit ihrer Gnade überhäuft hatte!

Morphy nahm am ersten New Yorker Turnier teil. Fin groBer 
Ruf ging ihm voraus, und der elegante rubige Spieler wurde sympathisch empfangen. Interesse für ihn erweckte schon seine äußere Erscheinung. Die glänzenden schwarzen Augen lieBen es schier ahnen, daB hinter der ungewöhnlich hohen Stirn ein wunderbarer Verstand seinen Sitz haben müsse. Sein anscheinend schwacher Körperbau verbarg groBe Zzhigkeit und Ausdauer. Die wohlbekannten und oft sich wiederbolenden Verschrobenheiten des Genies fehlten bei ihm. In schönsten Rahmen, im Rahmen der Liebenswürdigkeit, der Bescheiden. heit, der GroBmut, lieB er sein 'Talent glänzen. Jene werden nur bewundert, er wurde liebend verebrt. - Das Turnier zu New York be. stătigte seine auBergewöhnliche Begabung. In rascher Folge besiegte er seine Gegner und wurde mit spielender Leichtigkeit der Erste.

GroBartig war sein Spiel! In der Erơffnung brachte or auf die geschickteste Weise erfinderisch seine Offiziere ins Gefecht. $\mathrm{Zu}$ diesem Zwecke schreckte er auch vor einem Baueropfer nicht zurück, selbst wenn damit unmittelbar kein Vorteil verbunden zu sein schien. Sein feines Positionsgefühl sicherte ihm ein gesundes Mittelspiel, wo er das meiste Terrain batte zar Betătigung seines Genies.

Die moderne Schule bemüht sich mit beinahe wissenschaft. licher Peinlichkeit einen minimalen Vorteil zum Gewinn zu steigern. Auch Morphy mit seinem künstlerischem Sinn gewahrte die ge. ringste Schwäche in der Stellung des Gegners, um dann in glänzendem Stile zu siegen. Er brachte den allgemeinen Satz auch im Schach zur Geltung, daB das Beste stets auch das Schönste sei. Er hatte keine ausgesprochene Vorliebe für einzelne Figuren, höchstens für die Dame, die bei seiner Führung eine gewaltige Kraft entfaltete. Seine Über. legenheit erlaubte ihm gewöhnlich, sie zu behalten.

In seinem Spiel jagte eine Kombination die andere. Oft konnten seine Gegner den dramatischen Gang seiner Partien beobachten, die Entfaltung, die Vorbereitung der entscheidenden Kombination, den raschen Angriff und die Katastrophe. Vielleicht im Endspiel war die geringste Differenz zwischen ihm und seinen \%eitgenossen; die kalte Berechnung war bei weitem nicht so sein Element, als die Kombination.

Oft war und ist es auch jetzt ein Gegenstand der Diskussion, ob Morphy in der Gegenwart Erfolge würde erzielen können. Diejenigen, die es leugnen, denken an seine inkorrekten Opfer; diejenigen, die es behsupten, an sein Genie. Es ist unleugbar, dab inkorrekte Opfer 
in Morphys Partien oft vorkommen. Aber wie das frübzeitige und meistens erfolglose Opfern ein gewisses Stadinm in der Entwickelung des einzelnen Schachspielers bildet, so gab es auch in der Geschichte des Spieles selbst eine Epoche, da die verborgenen und viele Variationen bietenden Kombinationen einen sicheren Erfolg verschefften, weil die Gegner die langatmige and schwierige Verteidigung nicht finden konnten. Heutzutage gelingt es seltener, durch ein inkorrektes Opfer die Partie zu gewinnen, da die durch die Niederlagen ihrer Vorgănger gewitzigten Spieler in den meisten Fallen die richtige Verteidigung herausfinden, wenn sie auch noch so verborgen ist. Einen schwereren, viel schwereren Stand batte Iforphy gewiß gegen die modernen Spieler, aber sein machtiges Talent wiirde unbedingt auch ihn in die Elite der Mester erbeben.

Bald wurde Ameriks zu eng für den jungen Meister. Sein Ruf drang herüber nach Europa und im Juni 1858 kam er selbst, um deu ihm vorausgehenden Ruf zu übertreffen. Er wollte die Waffen mit jedem namhaften Spieler kreuzen, und jeder muBte seine überlegene Kraft füblen und anerkennen.

Er wollte der einzige Fürst im Reiche des Schachs sein und erreichte es auch.

Der erste Schauplatz seines Auftretens in Europs war London, wo er sich mit Howard Staunton messen au können hoffte. Die starkeren Spieler Englands versuchten der Reihe nach alsbald ihre Kraft an ihm, aber das Ergebnis war immer dasselbe: die Niederlage. Auch der aus Ungarn stammende berühmte Meister Löwenthal nahn mit anerkennenswerter Entschlossenheit den Handschuh auf und stellte ehrlich seinen Mann. Von 19 Spielen gewann Morphy 10, Lðwenthal 4 und fünf wurden remis. Niemand errang später ein so gutes Ergebnis gegen den Amerikaner. Nach dieser Niederlage Löwenthals war Staunton, der gehätschelto Götze der Englander, um keinen Preis mehr zu einem Wettkampf zu bewegen.

In Ermangelung ernsten 3pieles spielte Morphy in England Simultan- und Blindlingspartien. Hauptsächlich zeigte sich seine Größe in gleichzeitigen Blindlingsspielen. In Birminghsm versuchte or sich am 27. August 1858 gegen 8 ausgewahlt starke Spieler und gewann 7 Partien. Er unterhielt die Schachwelt, setzte sie in Erstaunen, bemerkte aber leider die Schädlichkeit der übermaBigen Geistesarbeit nicht. Als ihm für den Fall seiner Beteiligung am Turnier der British 
Chess Association in Birmingham ein Betrag als Ersatz seiner Unkosten nngeboten wurde, lehnte er dies Anerbieten mit der Begründung ab, daE er kein Professionsspieler sei.

Im Monat September 1858 reiste Morphy nach Paris. Der Kampfplatz und die Gegner wechselten, aber der Sieg war gerade so vollständig wie früber. Er kämpfte hier nicht nur mit den französischen Spielern, sondern mit allen denen, die nach Paris kamen, un mit ihm zu spielen. Auch der ausgezeichnete dentsche Schachmeister Anderssen muBte seine Kruft fühlen. Als Anderssen in Paris ankam, war Morphy mehrere Wochen bettlagerig gewesen und durfte das Zimmer noch nicht verlassen. Der denkwürdige Wettkampf muBte daher in dem Hotel Breteuil, in dem Morphy wohnte, in Gegenwart von Pariser Schachgrößen als Zeugen vor sich gehen. Morphy siegte mit 7:2 bei 2 Remisen. Sein Match gegen D. Harrwitz wirft ein interessantes Licht auf seinen Charakter. Der Wettkampt neigte sich schon dem Ende zu, da Morphy einen Stand von 5 gegen 2 erreicht hatte, als Harrwitz, Krankheit vorschützend, sich ergab. Der ritterliche Gegner nahm deshalb den Finsstz nicht an. Einen ahnlichen Fall weiB die Schachgeschichte nicht zu berichten.

Im Frübjabr 1859 nahm Morphy nochmals einen kurzen Aufenthalt in London, von wo er am 29. April nach seiner Heimat zurückkehrte, die Bewunderung sowohl der Zuschauer ais auch der Besiegten nit sich nehmend.

In seinem Heimatlende wurden ihm zu Ehren große Feierlichkeiten veranstaltet. Kehrte er doch als siegreicher Feldherr zurück, der die ganze Schachwelt erobert hatte!

Mit dieser ersten europaischen Reise beschloB Morphy seine schschliche Laufbahn, denn von nun an enthielt or sich ernster Kämpfe. Im Oktober $1862 \mathrm{kam}$ er wieder nach Paris, da er aber keine Rolle mehr im Schachleben spielen wollte, lehnte er jede Herausforderung ab. Im Frühjahr 1865 kehrte er in seine Vaterstadt zurück. Zum dritten Male ging er im Jahre 1867 nach Paris nnd brachte dort 18 Monate zu, ohne das wahrend seiner Anwesenheit stattfindende internationale Turnier anch nur zu besuchen. Nach New Orleans heimgekehrt, lebte or dort zurückgezagen und einsam bis zu seinem am 10. Juli 1884 erfolgten Tode.

Das Schach war die Ursache sowohl seines Weltrufs, seines Rubms, als auch seines tragischen Geschickes.

Sein Leben war wahrlich tragisch! Den Jüngling schlägt die Schön- 
heit des Spiels und die ihm bei seiner Ausübung zuteil werdende Bewunderung der Welt in seine Banden, doch als der Mann auf die Vergangenheit zurückschaut und sich prüft, bemerkt er mit Schrecken, daB die Würfel gefallen sind. Er ist tot für ernste Berufstätigkeit; es will ihm nicht gelingen, $z u$ ihr zurückzukehren.

Immer mehr wird er der Sklave des quälenden Gedankens, daß sein Leben zwecklos und verfehlt sei. Und er, dessen hellen Verstand so viele bewundert hatten, verlebt die letzle Zeit seines Lebens in ewiger Nacht. - -

In der Wissenschaft batte er vielleicht Schätze, Wahrheiten finden kőnnen: statt dessen grub er sich sein eigenes frühes Grab. Sein kurzes ruhmvolles Auftreten hat dsrauf ewig blühenden Schmuck gehäuft.

Morphys GroBvater wanderte am Ende des XVIII. Jahrhunderts aus Madrid in die Neue Welt ein und lieB sich in der Stadt Cbarleston in SüdCarolins nieder. Dem tatkräftigen, rührigen Manne gelang es sehr bald, seine Existenz zu sichern, and wegen seiner Gewandtheit, besonders in Staataangelegenheiten, ward er wiederholt durch das Vertrauen seiner Landsleute ausgezeichnet; er vertrat und verteidigte noch im Anfang des XIX. Jahr. hunderts viele Jahre hindurch im Staate Louisiana die Interessen seiner spanischen Heimst. - Sein älterer Sohn Alonzo war noch zu Charleston im Jahre 1798 geboren, aber wir finden ihn schon in seiner frulhesten Jugend in New Orleans, wo er in dem französischen Lehrinstitute "Collége d'Orléans" seine Vorstudien für die Recbtswissenschaft absolvierte. Die Bemuhungen des fleißigen, strebssmen Jünglings krönte ein glänzender Erfolg auf seiner späteren Laufbahn. Als stark gesuchter Anwalt an südamerikanigchen Gerichtshöfen tätig, erwarb er nicht nur ein großes Vermögen, sondern auch Sitz und Stimme in der gesetzgebenden Körperschaft von Louisiana; von 1840-46 war er Mitglied des obersten Gerichtshof's in diesem Staate. - Dann zog er eich zurück und lebte bis zu seinem Tode 1856 der Erziehung seiner Kinder, die ibm aus der Ehe mit der feinsinnigen und geistig hoch veranlagten Kreolin Thelcide Carpentier, der Tochter des Franzosen Joseph le Carpentier, entsprossen waren. Die drei blühenden Abkommlinge besaßen in glücklicher Mischung nicht nur den ernsten, praktischen und energischen Charakter des Vaters, sondern auch die reiche Phantasie und das feine Taktgefühl der Mutter, die vermöge ibres künstlerisch hervorragenden Pianospieles und ihrer bewunderten eigenen Kompositionen in hohem Ansehen stand. - Als Freund des Schachspieies war Alonzo Morphy bemüht, die edle Erholung auch bei seinen zwei Söhnen, Edward und Paul, beliebt zu machen, ja sogar seine Tochter Helena suchte hierin uach ermüdenden Musikstudien ihre Zerstreuung. - Der Unterricht des Vaters und des Onkels Erneet Morphy fiel bei unserem Helden anf einen fruchtbaren Boden. - Der Schüler übertraf bald seine Meister. 